\title{
Travel Format versus Nationality as Drivers of the Perception of Crowding in a Rural Tourist Destination
}

\author{
By Else Ragni Yttredal ${ }^{*} \&$ Nathalie Homlong ${ }^{ \pm}$
}

\begin{abstract}
Internationally many tourist destinations, both in cities and in rural areas, are confronted with the problem of heavy visitation, which tourists might perceive as crowding. In previous studies different factors have been investigated as drivers of the perception of crowding. This study focuses on travel format (individual travel on land versus group cruise travel) and nationality. A survey was carried out in the rural tourist destination of Geirangerfjord in Western Norway, where a village of 235 inhabitants hosts almost one million tourists every year. Among key findings was that travel format is a significant driver of perceived crowding, whereas nationality can only to a limited degree explain variations. In addition to this, travel format is a moderating factor between the perception of crowding and certain aspects of visitor satisfaction. Explanations of the findings are connected to a "site customization factor", a "personality factor", an "expectation factor" and an "exposure factor", all factors close to the visitors' perception and experience. In this way the study adds to and deepens the understanding for the mechanisms behind perceived crowding.
\end{abstract}

Keywords: crowding, nationality, travel format, visitor management, cruise travel

\section{Introduction}

Popular tourist attractions with a mix of visitors coming by cruise ships and traveling on land, like Venice and Barcelona have experienced major challenges related to crowding (see e.g., Garay et al. 2014, Russo 2002). Such challenges are not confined to larger metropolitan areas. In rural Norway, rural cruise destinations such as Geirangerfjord, Flåm, and Svalbard, represent unique challenges to visitor planning in this regard. Identifying factors that influence the perception of crowding is therefore of key importance to visitor planning and management. In line with this, this study explores the relationship between nationality, travel format and perception of crowding.

Congestion and crowding are terms often used interchangeably in the context of heavy visitation to tourist attractions. The two terms however point to different aspects of visitor density. Congestion relates to the physical conditions of high visitation. Visitation numbers are typically a way to describe congestion (Manning and Lime 1996). The term can also be a description of situations when the infrastructure of a tourist site reaches its limits of capacity and visitors compete for the use of services or parking spaces (Lime et al. 1996, p. 10). Crowding, on the other hand, relates to tourists' perception of the presence of other tourists. The

\footnotetext{
* Researcher, Department of Planning and Administration, Volda University College, Norway. ${ }^{ \pm}$Professor, Department of Planning and Administration, Volda University College, Norway.
} 
concept of crowding comprises both descriptive information, relating to the density or number of tourists in a tourist site, and evaluative information - an individual's interpretation of the density of tourists (Vaske and Shelby 2008). As a psychological construct, perceived crowding lies within the mind of individuals. Visitors' perception of crowding in a tourist site is therefore a comparison of the relevant indicators of congestion and visitor density with personal standards of acceptable visitation (Manning and Lime 1996, Vaske and Shelby 2008).

\section{Literature Review}

\section{Determinants of Perception of Crowding}

The threshold at which the number of other tourists is seen as disturbing varies among visitors. Personal or group standards may differ, and studies have identified various determinants of groups' and individuals' perception of crowding. Several studies show that nationality influences perception of crowding (see e.g., Jin et al. 2016, Kiliçarslan and Caber 2018, Sayan et al. 2013, Sun and Budruk 2017). Cultural differences are seen as the main reasons for these differences (Sayan et al. 2013). Tourists from cultures which are considered more collectivistic, such as from Asian and African countries, have been found to have a higher tolerance for crowding than more individualistic cultures, such as tourists from countries in Europe and North America (Jin et al. 2016). In addition to nationality, distance from the place of residence to the tourist destination is a factor that can influence perception of crowding (Arnberger and Brandenburg 2007). In line with this, prior experience and attachment to the destination lead to higher sensitivity to crowding - a characteristic rather in place with local visitors than with visitors whose residence is further away from the tourist site (Eder and Arnberger 2012, p. 574).

Travel format relates to the composition of the visitor group - free and independent travel versus group travel in package tours is a main distinction (Sun and Budruk 2017). In the case of package tours itineraries are set beforehand. The tourists purchase a bundle of services - e.g., air travel, accommodation and other services - from a travel retailer (Hyde and Lawson 2003). For tourists this form of travel reduces risks connected to language and cultural barriers, and the needs to acquire information and for orientation in an unfamiliar setting. At the same time package tours go hand in hand with larger groups, which in turn add to congestion and crowding in the tourist site (Sun and Budruk 2017). Research on the influence of travel format is scarce (Sun and Budruk 2017). There is some research on the experience of crowding for certain types of transport and travel mode, for example of cruise tourists (Sanz-Blas et al. 2019). Some research indicates that group travelers tend to have a higher tolerance than individual travelers of being surrounded by other tourists. This was for example shown in a study conducted in a German national park (Kalisch and Klaphake 2007). A study about the satisfaction of individual travelers versus package tours in Vietnam on the other 
hand found that travel format did not influence perception of crowding (Truong and Foster 2006).

A range of other factors potentially influence perception of crowding. Sociodemographic characteristics of the visitors are found to be a factor (Moyle and Croy 2007, p. 520). Activities that visitors are engaged in at the tourist site and characteristics of the site is another aspect (Moyle and Croy 2007, p. 520). Major motivations for undertaking a visit, as well as expectations about the level of crowding at the tourist site were found to influence the perception of crowding in several studies (Zehrer and Raich 2016, p. 92). Typically, perception of crowding has a tendency to be different among visitors who seek solitude in contrast to those who state social interaction as a motive for their visit (Arnberger and Haider 2007, p. 669). Characteristics connected to encounters with other tourists also tend to play a role in the perception of crowding. Where the encounter takes place is relevant. For example, front-country users are willing to tolerate more tourists than backcountry users (Popp 2012, p. 52). The number of perceived encounters has an effect (Kalisch and Klaphake 2007, p. 110). Also, the behavior of encountered tourist groups, e.g. with respect to noise and littering, and types of visitors met were shown to influence whether visitors tolerated other visitors in the same tourist site and in which number (Cole and Hall 2009, pp. 29-32, Manning and Lime 1996, pp. 29-31). Investigations into the effect of length of stay have been performed by several studies. Typically, only small differences are found, but in a study of wilderness visitors, day visitors were less likely to be sensitive to crowding than overnight visitors (Cole and Hall 2008, p. 35).

\section{Crowding and Visitor Satisfaction}

Congestion and perceived crowding can limit tourists' ability to engage in desired activities, lead to undesired social contacts and stimulus overload (Kiliçarslan and Caber 2018, p. 58, Sanz-Blas et al. 2019). Due to the potential negative impacts of crowding on the visitor experience, crowding is an important element in visitor satisfaction. This is especially the case in protected natural areas, where visitors tend to expect solitude and privacy (Cole and Hall 2008, pp. 12-15, Moyle and Croy 2007, p. 519). While crowding typically is seen as negative, this is not always the case - e.g. in bars and sports stadiums crowding has been found to be perceived in a positive way (Kiliçarslan and Caber 2018, p. 56, Popp 2012). Also, even in wilderness areas where visitors tend to seek solitude, most visitors do not wish for complete isolation, but would rather experience wilderness in small groups - "alone together" (Cole and Hall 2010, p. 67). A distinction between negative and positive crowding is thus made (Popp 2012).

Also increased visitation does not automatically result in degraded visitor experiences. This was demonstrated by a series of studies carried out in the same tourist locations, several years apart or over several years. They showed that even though visitor density had increased over time, the perception of crowding was less negative (Kuentzel and Heberlein 2003, Vaske and Shelby 2008, p. 113). Changes of standards of acceptable visitation may partly explain these results. In addition, visitors, especially those most sensitive to crowding, tend to use coping 
strategies to deal with heavy visitation. These coping mechanisms include actions like relocation to other tourist sites, choosing a different time to visit, engaging in different activities than would have been chosen in less crowded settings, and rerationalization and redefinition of the experience and standards of the visit (Moyle and Croy 2007, pp. 520-521).

\section{Hypotheses}

The aim of this study is to explore to what degree and how nationality and travel format influence tourists' perception of crowding. Based on literature and previous research, two hypotheses were formed:

1. Nationality influences visitors' perception of crowding based on cultural differences and distance.

2. Travel format (represented by cruise travelers and individual travelers on land) influences visitors' perception of crowding.

\section{Stylized Facts - Study Area}

In 2005, Geirangerfjord together with Nærøyfjord was inscribed on the UNESCO World Heritage List as "West Norwegian Fjord Landscape". As one of Norway's most visited destinations, especially within nature-based tourism, Geirangerfjord is an icon of tourism in Norway. Only 235 people live year-round in the village of Geiranger (Statistics Norway 2019), while the number of visitors to the area was estimated at around 1 million in 2018 (Yttredal et al. 2019). The inhabitant-visitor ratio is then approximately 1:4200 per year, while a ratio of 1:5.3 or more is estimated to be a high-risk tourism intensity in cities (McKinsey \& Company and World Travel \& Tourism Council 2017, p. 22). Tourists are mainly visiting during the summer months of June, July and August. In the peak of month of July, an average of about 10,000 people, visit Geirangerfjord daily. Even in this peak period, however, the number of visitors and therefore congestion fluctuates depending on the time of the day. There is a peak number of visitors between 11:00 am and 7:00 pm, with an extra peak between 1:00 pm and 5:00 pm (Yttredal et al. 2019). This is also the time period in which most cruise ships dock. Visitors who come to Geiranger during peak season but outside this time period, can experience the center of Geiranger as quiet, peaceful and almost empty. The extent of congestion and crowding also varies geographically, with a concentration of visitation in the center of the village Geiranger and on main attractions. 
Figure 1. Map of the Geiranger Area as Defined in the Study

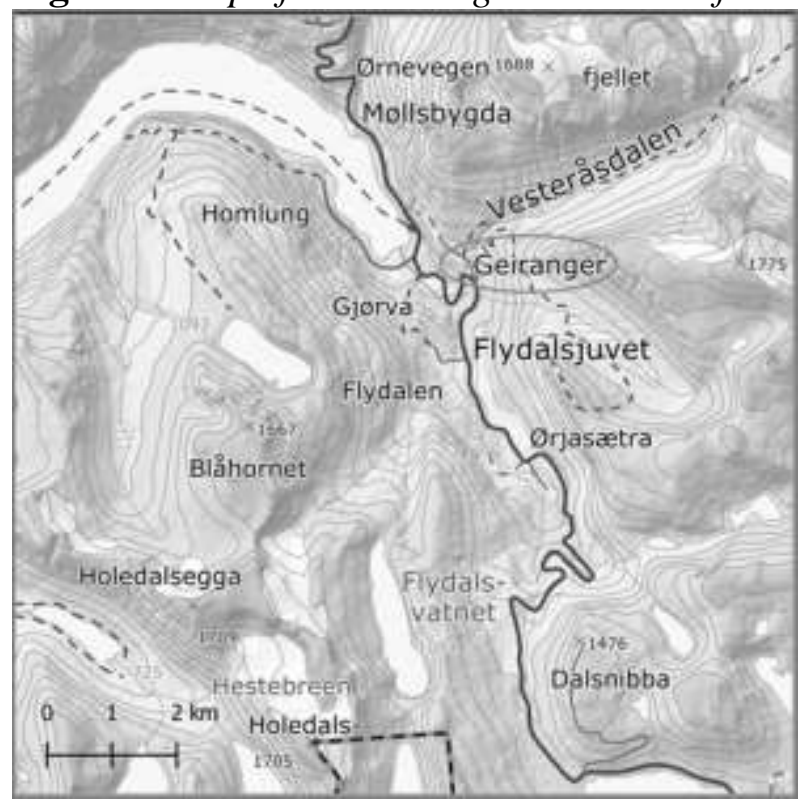

Source: WMS @ Kartverket.

Geirangerfjord and the village of Geiranger are surrounded by steep mountains. To enter Geiranger village, which is the center of the destination, visitors can use one of three access ways - two by narrow and winding roads from the North and South, and the fjord - either by cruise boat or by car ferry (Figure 1). In recent years, the number of cruise passengers has been restricted by limitations on the number of ships per day and was in 2017 and 2018 stable at just below 350,000 (Yttredal et al. 2019). Cruise thus contributes to roughly one third of the visitors to the area.

\section{Methodology}

\section{Data Collection}

Data was collected in the Geiranger area Mondays through Fridays between July $9^{\text {th }}$ and August $3^{\text {rd }}, 2018$. The period of data collection thus covered both peak season for leisure visitation during the period of general Norwegian staff vacation, and daily peak visitation period. Questionnaires were only handed out to visitors on their way out of the area, to make sure that they had completed their travel experience in Geiranger. To make clear which area was the subject of inquiry, a map was included in the questionnaire. The participants in the survey could choose between several languages, namely Norwegian, English, German, French, Spanish, and Mandarin. 474 tourists answered questionnaires digitally on tablets or by link.

The questionnaire included several aspects related to perception of crowding and congestion, such as noise, traffic congestion, access to transportation services and parking. The survey also included questions on overall satisfaction - 
willingness to recommend the tourist destination and whether nature experiences lived up to expectations. All questions were formed as assertions using a five-point Likert scale ranging from 1 "completely disagree" to 5 "completely agree." The question on perceived crowding was phrased to make sure that it was negative crowding the respondents related to (Popp 2012).

\section{The Sample}

Table 1. Socio-Demographic and other Background Variables of the Sample. Percent of Total, Cruise Visitors and Individual Travelers on Land $(N$ Total $=$ $474)^{1}$

\begin{tabular}{|c|c|c|c|c|}
\hline Variable & Values & $\begin{array}{c}\text { Percent of } \\
\text { total } \\
\text { sample }\end{array}$ & $\begin{array}{c}\text { Percent of } \\
\text { cruise } \\
\text { visitors }\end{array}$ & $\begin{array}{l}\text { Percent of } \\
\text { ind. land }\end{array}$ \\
\hline \multirow[t]{2}{*}{ Transport mode to area } & Cruise passengers & 29 & & \\
\hline & Individual travelers on land & 71 & & \\
\hline \multirow[t]{2}{*}{ Gender } & Female & 46 & 48 & 45 \\
\hline & Male & 54 & 52 & 55 \\
\hline \multirow[t]{3}{*}{ Highest level of education } & High school or lower & 29 & 28 & 29 \\
\hline & Bachelor degree & 31 & 26 & 33 \\
\hline & Master or higher & 40 & 45 & 38 \\
\hline \multirow[t]{4}{*}{ Household income per year } & Lower than 40,000 EUR & 21 & 24 & 20 \\
\hline & 40,000-79,999 EUR & 31 & 22 & 35 \\
\hline & 80,000-119,999 EUR & 26 & 23 & 27 \\
\hline & 120,000 EUR and above & 22 & 30 & 18 \\
\hline \multirow[t]{3}{*}{ Age } & $0-34$ years & 36 & 31 & 38 \\
\hline & $35-54$ years & 43 & 41 & 44 \\
\hline & 55 years or older & 21 & 28 & 18 \\
\hline \multirow[t]{2}{*}{ Day-visitor or overnight stay } & Day-visitor & 58 & 100 & 40 \\
\hline & Overnight stay & 48 & 0 & 60 \\
\hline \multirow[t]{5}{*}{ Country of residence } & Norway & 24 & 6 & 32 \\
\hline & Germany & 22 & 33 & 17 \\
\hline & $\begin{array}{c}\text { Other western European } \\
\text { countries }\end{array}$ & 36 & 30 & 38 \\
\hline & North America & 8 & 23 & 2 \\
\hline & Others & 10 & 8 & 11 \\
\hline
\end{tabular}

Source: Own data collection.

\footnotetext{
${ }^{1}$ The sample includes mainly respondents from Western Europe, USA and Canada. The main reason for this is that cruise-passengers and visitors traveling individually on land are mainly from Western countries (Europe and North America), while for example Asian tourists travel mostly in groups by bus. This study focuses exclusively on cruise tourists and individual travelers on land (418 respondents). Bus tourists are excluded from the analysis.
} 
The proportion of cruise visitors $(29 \%)$ in the sample reflects the proportion of the total number of visitors quite well. The respondents have a broad and relatively even distribution of socio-economic background factors, such as gender, education, income and age. The proportion of day visitors is $58 \%$ while $42 \%$ percent have stayed overnight (Table 1).

\section{Method of Analysis}

To test hypothesis 1, "nationality influences visitors' perception of crowding" several subsequent comparisons of perception of crowding between Norwegian visitors and other countries or groups of countries were performed. T-tests and Mann Whitney U tests were used, checking for differences of mean and median and the significance of these differences. To test hypothesis 2; "travel format (represented by cruise travelers and individual travelers on land) influences visitors' perception of crowding", comparisons of the perception of crowding were made between cruise passengers and individual travelers on land using T-tests and Mann Whitney U tests. The group "cruise passengers" consists of visitors arriving in the Geiranger area by cruise ship or by bus, but as part of a trip with a cruise ship. Crew from cruise ships was excluded. The group "individual travelers on land" includes visitors arriving to the area by road or ferry mainly using car or motorhome but also motorbikes, public bus transportation or by foot or bicycle.

In the dataset, nationalities arriving in the Geiranger area on land are different from nationalities arriving by cruise ship (see Table 2). German visitors are the only nationality broadly represented both in the group of cruise passengers and in the group of travelers on land. To check for nationality as a confounding variable explaining differences in the sample as a whole, analysis was thereafter restricted to the German subgroup of the sample. The survey measures perception of crowding directly, but also includes other aspects of congestion like perception of parking and traffic congestion. It also includes measures of satisfaction. To understand more thoroughly the relationship between travel format, perceived crowding and other variables, several bivariate correlation analyses were performed for cruise passengers and individual travelers on land separately, and then compared. Both Pearson's r and Spearman's Rho were used. To have comparable group sizes and situations, the analysis was confined to day visitors only.

There is considerable controversy over the use of parametric methods to analyze datasets with dependent variables using Likert scales. Arguments are diverse both opposing (Bentz et al. 2016, Jamieson 2004, Oh 2001) and in favor (Bishop and Herron 2015, Carifio and Perla 2008, Knapp 1990, Murray 2013) of using such methods. Tests of the data from the Geiranger area show that the data are non-normally distributed and that especially the "satisfaction variables" are highly skewed, thus violating assumptions underlying parametric analysis. Furthermore, single Likert type variables are used both as criterion (dependent) and independent variables. To compensate for these characteristics of the dataset, both parametric and non-parametric methods are used in the analyses. The two methods in general create compatible results. 


\section{Results}

Visitors' overall impression of the Geiranger area is positive. 91\% of the visitors completely or partly agree that the nature experience lives up to their expectations and $87 \%$ would recommend the area as a tourist destination to others. When it comes to perception of crowding, $46 \%$ of the visitors completely or partly disagree with the assertion that "I did not experience the Geiranger area as too crowded". $43 \%$ completely or partly agree to the same assertion.

\section{Hypothesis 1: Nationality and Perception of Crowding}

Testing hypothesis 1: Nationality influences visitors' perception of crowding in the Geiranger area based on cultural differences and distance.

Table 2. Perceptions of Crowding. Norwegians and other Nationalities and Groups of Nationalities Compared (1="Completely Disagree" - 5="Completely Agree")

\begin{tabular}{|l|c|c|c|c|c|c|c|}
\hline & \multicolumn{5}{|c|}{ "I did not experience the Geiranger area as too crowded" } & \\
\hline & Mean & $\begin{array}{c}\text { Difference of } \\
\text { means to } \\
\text { Norwegians }\end{array}$ & $\begin{array}{c}\text { Sig. of } \\
\text { difference }\end{array}$ & Median & $\begin{array}{c}\text { Difference of } \\
\text { median to } \\
\text { Norwegians }\end{array}$ & $\begin{array}{c}\text { Sig. of } \\
\text { difference }\end{array}$ & $\mathrm{N}$ \\
\hline Norwegians & 2.58 & & & 2.00 & & & 89 \\
\hline All foreigners & 2.92 & 0.34 & 0.05 & 3.00 & 1.00 & 0.04 & 285 \\
\hline $\begin{array}{l}\text { Nordic countries } \\
\text { except Norway }\end{array}$ & 3.22 & 0.64 & 0.02 & 4.00 & 2.00 & 0.02 & 38 \\
\hline $\begin{array}{l}\text { Western Europe } \\
\text { except Nordic } \\
\text { countries }\end{array}$ & 2.81 & 0.23 & 0.22 & 2.00 & 0.00 & 0.20 & 175 \\
\hline $\begin{array}{l}\text { Distant visitors } \\
\text { (Asia, Oceania, } \\
\text { South America, } \\
\text { North America) }\end{array}$ & 3.05 & 0.47 & 0.05 & 3.00 & 1.00 & 0.05 & 59 \\
\hline $\begin{array}{l}\text { Southern Europe } \\
\text { (Italy, Spain, } \\
\text { France) }\end{array}$ & 2.56 & -0.02 & 0.93 & 2.00 & 0.00 & 0.93 & 34 \\
\hline Germany & 2.77 & 0.19 & 0.37 & 2.00 & 0.00 & 0.30 & 82 \\
\hline
\end{tabular}

Source: Own data collection.

Both a T-test $(\mathrm{p}=0.05)$ and a Mann Whitney U-test $(\mathrm{p}=0.04)$ analyzing the whole dataset show that there is a small but significant difference between Norwegian visitors' perceptions of crowding and all foreign visitors' perception of the same (Table 2). To check if and how distance influence the perception of crowding (Jin et al. 2016, Sayan et al. 2013), foreigners were grouped into Nordic visitors except Norway (Denmark, Sweden, Finland), Western European visitors except the Nordic visitors, and distant visitors (Asia, Oceania, South America, North America). There are significant differences of the perception of crowding between Norwegian visitors and other Nordic visitors ( $\mathrm{p}=0.02$ for both tests), and between Norwegian visitors and distant visitors ( $\mathrm{p}=0.05$ for both tests). There is no significant difference in the perception of crowding between Norwegian visitors 
and Western European visitors from outside the Nordic countries. Additional tests comparing Norwegians to Southern European (Italy, France and Spain) and German visitors showed no significant results.

\section{Hypothesis 2. Travel Format and the Perception of Crowding}

Testing hypothesis 2: Travel format (represented by cruise travelers and individual travelers on land) influences visitors' perception of crowding.

Table 3. Differences in Perception of Crowding between Cruise Passengers, Individual Travelers on Land (All) and Individual Travelers on Land (Day Visitors) (Scale: $1="$ Completely Disagree" - 5="Completely Agree")

\begin{tabular}{|l|c|c|c|c|c|c|c|}
\hline & \multicolumn{5}{|c|}{ "I did not experience the Geiranger area as too crowded" } & \\
\hline & Mean & $\begin{array}{c}\text { Difference } \\
\text { of means to } \\
\text { cruise } \\
\text { passengers }\end{array}$ & $\begin{array}{c}\text { Sig. of } \\
\text { difference }\end{array}$ & Median & $\begin{array}{c}\text { Difference } \\
\text { of median to } \\
\text { Cruise } \\
\text { passengers }\end{array}$ & $\begin{array}{c}\text { Sig. of } \\
\text { difference to } \\
\text { Cruise } \\
\text { passengers }\end{array}$ & N \\
\hline $\begin{array}{l}\text { Cruise } \\
\text { passengers }\end{array}$ & 3.19 & & & 4.00 & & & 118 \\
\hline $\begin{array}{l}\text { Ind. } \\
\text { travelers } \\
\text { land all }\end{array}$ & 2.71 & -0.48 & 0.00 & 2.00 & -2.00 & 0.00 & 283 \\
\hline $\begin{array}{l}\text { Ind. } \\
\text { travelers } \\
\text { land day }\end{array}$ & 2.47 & -0.72 & 0.00 & 2.00 & -2.00 & 0.00 & 112 \\
\hline
\end{tabular}

Source: Own data collection.

Analyzing differences in the perception of crowding for the whole dataset using a T-test and Mann Whitney U-test, there is a statistically significant difference of means and medians between cruise visitors and all independent travelers on land ( $\mathrm{p}=0.0$ for both tests) (Table 3 ). In the group travelers on land, there is a mix of day visitors and visitors staying overnight. Since cruise visitors are day visitors to the area, such a mix of visitors who stay over night and day visitors in the comparison group might influence the results. T-tests and Mann Whitney U-tests were therefore performed for day visitors only. The difference of means between cruise visitors and visitors traveling on land increases when the analysis is confined to day visitors $(-0.72)$, while the difference of median is the same (2.00). The difference of both median and mean is statistically significant $(\mathrm{p}=0.0)$. 
Table 4. Differences in Perception of Crowding between German Cruise Passengers and Germans Traveling Individually on Land (Scale: 1="Completely Disagree" - 5="Completely Agree")

\begin{tabular}{|l|c|c|c|c|c|c|c|}
\hline & \multicolumn{5}{|c|}{ "I did not experience the Geiranger area as too crowded." } & \\
\hline & \multicolumn{3}{|c|}{ T-test } & \multicolumn{3}{c|}{ Mann Whitney U } & \\
\hline & Mean & $\begin{array}{c}\text { Difference } \\
\text { of mean to } \\
\text { cruise } \\
\text { passengers }\end{array}$ & $\begin{array}{c}\text { Sig. of } \\
\text { difference }\end{array}$ & Median & $\begin{array}{c}\text { Difference } \\
\text { of median } \\
\text { to cruise } \\
\text { passengers }\end{array}$ & $\begin{array}{c}\text { Sig. of } \\
\text { difference } \\
\text { to cruise } \\
\text { passengers }\end{array}$ & N \\
\hline Cruise passengers & 3.18 & & & 4.00 & & & 38 \\
\hline Ind. Travelers land & 2.41 & -0.77 & 0.00 & 2.00 & -2.00 & 0.00 & 44 \\
\hline
\end{tabular}

Source: own data collection

Table 4 shows that there is a quite large and significant difference of means within the German group, with visitors traveling by cruise ship being less sensitive to crowding than those traveling individually on land. The results from the German group thus strengthen the findings that there is a difference in perception of crowding depending on travel format.

\section{Travel Format, the Perception of Crowding and Indicators of Satisfaction}

Finding significant and quite large differences between travel format and the perception of crowding made it expedient to look deeper into possible dissimilarities between cruise passengers and individual travelers on land also for other variables.

Table 5. Bivariate Correlations between the Perception of Crowding and Overall Satisfaction (Scale: 1="Completely Disagree" - 5="Completely Agree")

\begin{tabular}{|c|c|c|c|c|c|c|}
\hline & \multicolumn{5}{|c|}{ "I did not experience the Geiranger area as too crowded." } & \\
\hline & \multicolumn{2}{|c|}{ Cruise passengers } & & \multicolumn{3}{|c|}{ Individual travelers on land day } \\
\hline & $\begin{array}{c}\text { Pearson } \\
\text { Correlation } \\
\end{array}$ & $\begin{array}{c}\text { Spearman's } \\
\text { Rho } \\
\end{array}$ & $\mathrm{N}$ & $\begin{array}{c}\text { Pearson } \\
\text { Correlation }\end{array}$ & $\begin{array}{c}\text { Spearman's } \\
\text { Rho }\end{array}$ & $\mathrm{N}$ \\
\hline $\begin{array}{l}\text { I would recommend the } \\
\text { Geiranger area as a } \\
\text { holiday destination to } \\
\text { others. }\end{array}$ & 0.06 & 0.09 & 117 & $0.32 * *$ & $0.39 * *$ & 110 \\
\hline $\begin{array}{l}\text { The nature experience of } \\
\text { the Geiranger area lived } \\
\text { up to my expectations. }\end{array}$ & -0.02 & -0.03 & 117 & $0.32 * *$ & $0.34 * *$ & 110 \\
\hline
\end{tabular}

*=sig. at a 0.05 level

$* *=$ sig. at a 0.01 level

Source: Own data collection.

Table 5 shows bivariate correlations between the perception of crowding and variables indicating overall satisfaction with the stay. The analysis is confined to day visitors. Pearson's $r$ and Spearmans' Rho are based on different assumptions, but are in this case coinciding when it comes to detecting significant correlations. A medium strong and significant correlation between the perception of crowding 
and indicators of overall satisfaction is found; Pearson's r $=0.32$ and Spearman's Rho $=0.39$ and 0.34 for the two variables. For cruise passengers there are no significant bivariate correlations between perception of crowding and measures of overall satisfaction.

Table 6. Bivariate Correlations between the Perception of Crowding and Perception of Other Variables related to Congestion (Scale: 1="Completely Disagree" - 5="Completely Agree")

\begin{tabular}{|l|c|c|c|c|c|c|}
\hline & \multicolumn{5}{|c|}{ "I did not experience the Geiranger area as too crowded." } & \\
\hline & \multicolumn{2}{|c|}{ Cruise passengers } & \multicolumn{3}{c|}{ Individual travelers on land day } \\
\hline & $\begin{array}{c}\text { Pearson } \\
\text { Correlation }\end{array}$ & $\begin{array}{c}\text { Spearman's } \\
\text { Rho }\end{array}$ & $\mathrm{N}$ & $\begin{array}{c}\text { Pearson } \\
\text { Correlation }\end{array}$ & $\begin{array}{c}\text { Spearman's } \\
\text { Rho }\end{array}$ & $\mathrm{N}$ \\
\hline $\begin{array}{l}\text { It was easy to get access } \\
\text { to transportation services } \\
\text { in the Geiranger area. }\end{array}$ & 0.11 & 0.17 & 94 & $0.257^{*}$ & $0.276^{*}$ & 66 \\
\hline $\begin{array}{l}\text { It seems easy to find a } \\
\text { place to park in the } \\
\text { CENTER of Geiranger. }\end{array}$ & 0.16 & 0.19 & 46 & $0.47^{* *}$ & $0.49^{* *}$ & 80 \\
\hline $\begin{array}{l}\text { Traffic congestion (DID } \\
\text { NOT) negatively } \\
\text { influences my impression } \\
\text { of the Geiranger area. }\end{array}$ & $0.32^{* *}$ & $0.32^{* *}$ & 98 & $0.31^{* *}$ & $0.33^{* *}$ & 105 \\
\hline $\begin{array}{l}\text { Noise does not seem to be } \\
\text { a problem in the } \\
\text { Geiranger area. }\end{array}$ & $0.32^{* *}$ & $0.29^{* *}$ & 117 & $0.37^{* *}$ & $0.38^{* *}$ & 104 \\
\hline
\end{tabular}

Table 6 shows bivariate correlations between the perception of crowding and other parameters relating to congestion. For cruise passengers, perceived crowding is significantly correlated with parking (Pearson's $r=0.32$, Spearman's rho $=0.32$, $\mathrm{p}<0.01$ ) and noise (Pearon's $\mathrm{r}=0.32$ ad Spearman's Rho=0.29, $\mathrm{p}<0.01$ ). For individual day travelers on land, crowding is also correlated with access to transportation services (Pearson's $r=0.26$ and Spearman's Rho $=0.276, p<0.05$ ) and strongly correlated with parking (Pearson's $r=0.47$, Spearman's rho $=0.49, \mathrm{p}<0.01$ ).

\section{Discussion}

Firstly, the results do not support hypothesis 1: Nationality of visitors influences the perception of crowding due to cultural differences and distance from the tourist destination. There is very little evidence suggesting that there are large differences of perception of crowding between groups of countries or single countries. In addition, there is no distinct pattern suggesting that perception of crowding is increasingly positive with distance or is different due to cultural differences. For instance, compared to visitors from the most distant countries, Norwegians are more critical to crowding. This is consistent with the hypothesis. However, visitors from the Nordic countries, who should be the closest to 
Norwegians both culturally and geographically, are also more tolerant to crowding than Norwegian visitors, while other Europeans are less.

Secondly, the results strengthen hypothesis 2: Travel format (represented by cruise travelers and individual travelers on land) covaries with the perception of crowding. There is a significant and quite large difference in perception of crowding between group visitors arriving by cruise ship, and individual travelers on land. Furthermore, travel format seems to be a moderating factor (Baron and Kenny 1986) for the relationship between perceived crowding and indicators of overall satisfaction (nature experience and willingness to recommend). The same is the case for the relationship between perceived crowding and the perception of parking and access to transportation services. Travel format does not seem to moderate the relationship between perception of crowding and perception of traffic congestion or noise.

Figure 2. The Relationship between Travel Format, Perceived Crowding and Other Variables related to Visitor Experience and Satisfaction

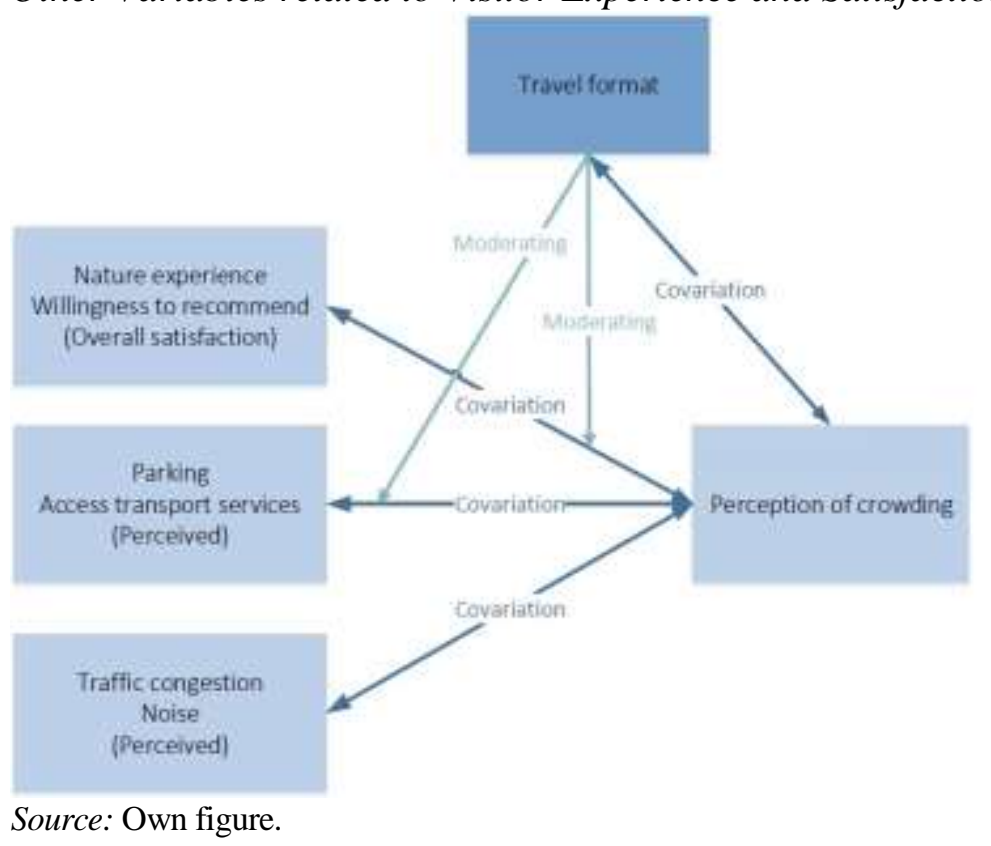

The relationships are illustrated in Figure 2. The causal directions between the variables in the analysis are not possible to determine from the analysis. The relationship between the variables can also be a type of cluster effect, variables covarying without a clear causal connection.

\section{Mechanisms behind the Results}

There is no logical causal connection between the type of transport itself, represented by cruise travelers, and independent travelers on land, and perception of the area. However, as shown in the study in Geiranger, mode of transport is also a difference in travel format: Free and independent travel versus group travel by cruise ship (Sun and Budruk 2017). There are several dimensions in the literature 
that can help understand the relationship between travel format and the perception of crowding found in the study.

Sayan et al. (2013) show that visitors' tolerance for congestion differ. Such a difference could be manifested in the choice of travel format, with people choosing to travel by cruise ship being more tolerant to congestion than people traveling individually on land. Some studies support this assumption (Kalisch and Klaphake 2007). In this line of reasoning the differences of the perception of crowding between cruise tourists and tourists traveling on land could be explained by different personal preferences and personality traits. Such an understanding of the mechanisms could be called a "personality factor".

Previous research shows various relationships between knowledge, motivation, expectation, behavior and satisfaction (Gnoth 1997, Hsu 2009, Huang et al. 2015). The results can then also be understood on the basis of an "expectation factor". The expectation factor consists of at least two dimensions. One dimension relates to the choice of vacation form. A cruise ship to the Geiranger area often has between 2000 and 5000 passengers (Information from Stranda Port Authority). This means that visitors choosing this mode of transport are surrounded by large numbers of fellow travelers throughout their journey. When visitors choose group travel on a cruise ship, they do not and cannot expect to be alone. The other dimension is related to the destination. Zehrer and Raich (2016) show that expectations about the destination influence the perception of crowding. Most individual travelers on land need to have a minimum of knowledge about individual destinations to organize their trip - leading to pre-travel expectations. On the other hand, cruise travels are organized and mediated by a tour operator. Individual cruise tourists' expectations for specific destinations might therefore not be as clear.

In addition, our data by itself indicate that there is an "exposure factor". The results show that exposure to negative experiences connected to one aspect of congestion and crowding seems to affect the perception of other relating factors. For instance, visitors traveling on land are, by definition, more prone to be exposed to parking problems than people traveling by cruise ships. Our analyses show that parking covaries with the perception of crowding only for visitors traveling on land. Furthermore Figure 2 shows that the perception of crowding covaries with the perception of traffic congestion and noise both for cruise tourists and visitors arriving by cruise ship. While only visitors traveling on land are exposed to parking problems, also cruise travelers moving around the site can be exposed to (negatively) perceived noise and traffic congestion. Since there does not seem to be a clear causal effect between the variables, the data indicates that there is a cluster effect - an exposure factor. If visitors are exposed to one negative effect of congestion, they also perceive other factors related to congestion negatively.

When tourists first came to the Geiranger area in the second half of the 19th century, traveling on the fjord was the only way of entry. Because of this, tourism in the area has developed along with the increase of cruise tourism. Infrastructure, logistics, shops, guided tours and activities are adapted to visitors arriving by sea in bulks. Moyle and Croy (2007) found that such characteristics of the site 
influence the perception of crowding. A "site customization factor" thus seems to exist. Characteristics of the site intermediate between travel format and the perception of crowding. Such an assumption is strengthened by two additional findings: Moyle and Croy (2007) also find that the type of activities that visitors participate in can influence the perception of crowding, and Sanz-Blas et al. (2019) found that guides have a mediating effect on the perception of the area. This corresponds with how the destination Geirangerfjord is organized for cruise tourists. Many of them participate in pre-booked tours. They are then guided from the boat to already waiting transportation and are brought to the respective sites. In this way the exposure to negative crowding is minimized.

\section{Conclusion}

In this study we show that travel format is the most important driver of the perception of crowding in the Geiranger area. We identified four factors to understand our statistical findings; "a personality factor", "an expectation factor", "a site customization factor" and "an exposure factor". Thus, on an individual level, factors connected to expectations and personalities have explanatory power. On a system level, explanations related to the site itself cause differences in perceptions. In addition, travel format seems to implicate different exposures to the negative sides of crowding.

Drivers of perceived crowding are thereby close to the visitors' experience. They are about the visitors' expectations and preferences meeting experiences on site; traffic congestion versus smooth driving, about easily finding parking spaces, access to transportation services and about noise. Factors further away from the actual experience cognitively or physically, like nationality, do not seem to have the same effect on their perceptions. Our study in this way adds to and deepens existing knowledge on perceived crowding and contributes to the understanding of the mechanisms behind the perceptions.

Our findings have several implications for visitor planning. Firstly, they indicate that visitor planning should address crowding in different ways, depending on visitors' travel format. Furthermore, such planning should have the purpose of addressing the four factors identified above. In the Geiranger case, measures to address the personality factor could include directing persons with a low tolerance for crowding to parts of the area with few other visitors and at times outside the peak season or peak time of day. To address the expectation factor, information and marketing could build on images that portray the situation during peak visitation times realistically. Addressing the exposure factor and site customization factor includes an array of possible measures like traffic signs, additional parking spaces, limitations on the number of visitors and regulations.

\section{Acknowledgements}

This study was carried out as part of the SUSTRANS project (Sustainable 
Transportation in Rural Tourism Pressure Areas), funded by the Norwegian Research Council. Project partners were NTNU, SINTEF and Volda University College in Norway and the University of Bonn, Germany. The authors acknowledge and appreciate the contribution of partners in the project SUSTRANS - An integrated sustainability appraisal methodology for transportation in rural tourism pressure areas: Dina Aspen, Børge Heggen Johansen, Magnus Sparrevik, Jörg Löffler, Solveig Meland and Sahar Babri.

\section{References}

Arnberger A, Brandenburg C (2007) Past On-site experience, crowding perceptions, and use displacement of visitor groups to a peri-urban national park Environmental Management 40(1): 34-45.

Arnberger A, Haider W (2007) A comparison of global and actual measures of perceived crowding of urban forest visitors. Journal of Leisure Research 39(4): 668-685.

Baron RM, Kenny DA (1986) The moderator-mediator variable distinction in social psychological research: conceptual, strategic, and statistical considerations. Journal of Personality and Social Psychology 51(6): 1173-11182.

Bentz J, Lopes F, Calaco H, Dearden P (2016) Enhancing satisfaction and sustainable management: Whale watching in the Azores. Tourism Management 54(2016): 465476.

Bishop PA, Herron RL (2015) Use and misuse of likert item responses and other ordinal measures. International Journal of Exercise Science 8(3): 297-302.

Carifio J, Perla R (2008) Resolving the 50-year debate around using and misusing Likert scales. Medical Education 42(12): 1150-1152.

Cole DN, Hall TE (2008) Wilderness visitors, experiences, and management preferences: how they vary with use level and length of stay. USA: United States Department of Agriculture/Forest Service.

Cole DN, Hall TE (2009) Perceived effects of setting attributes on visitor experiences in wilderness: variations with situational context and visitor characteristics. Environmental Management 44(1): 24-36.

Cole DN, Hall TE (2010) Privacy functions and wilderness recreation: use density and length of stay effects on experience. Ecopsychology 2(2): 67-75.

Eder R, Arnberger A (2012) The influence of place attachment and experience use history on perceived depreciative visitor behavior and crowding in an urban national park. Environmental Management 50(4): 566-580.

Garay LA, Canoves G, Prat J (2014) Barcelona, a leader destination in cruise-passenger tourism: keys, impacts and facts. International Journal of Tourism Sciences 14(1): 23-49.

Gnoth J (1997) Tourism motivation and expectation formation. Annals of Tourism Research 24(2): 283-304.

Hsu CHC, Cai LA, Li M (2009) Expectation, motivation, and attitude: a tourist behavioral model. Journal of Travel Research 49(3): 282-296.

Huang SS, Afsharifar A, van der Veen R (2015) Examining the moderating role of prior knowledge in the relationship between destination experiences and tourist satisfaction. Journal of Vacation Marketing 22(4): 320-334.

Hyde KF, Lawson R (2003) The nature of independent travel. Journal of Travel Research, 42(1): 13-23. 
Jamieson S (2004) Likert scales: how to (ab)use them. Medical Education 38(12): $1217-$ 1218.

Jin Q, Hu HH, Kavan P (2016) Factors influencing perceived crowding of tourists and sustainable tourism destination management. Sustainability 8(10): 976-993.

Kalisch D, Klaphake A (2007) Visitors' satisfaction and perception of crowding in a German National Park: a case study on the island of Hallig Hooge. Forest Snow and Landscape Research 81(1): 109-122.

Kiliçarslan D, Caber M (2018) The impacts of perceived crowding, the atmospherics of visitor satisfaction at cultural heritage sites: a comparison of Turkish and British visitors to Topkapi Palace, Istanbul. Journal of Tourism and Services 9(17): 55-75.

Knapp TR (1990) Treating ordinal scales as interval scales: an attempt to resolve the controversy. Nursing Research 29(2): 121-123.

Kuentzel WF, Heberlein TA (2003) More visitors, less crowding: change and stability of norms over time at the Apostle Islands. Journal of Leisure Research 35(4): 349-371.

Lime DW, McCool SF, Galvin DP (1996) Trends in congestion and crowding at recreation sites. In DW Lime (ed.), Congestion and Crowding in the National Park System. St. Paul: University of Minnesota.

Manning RE, Lime DW (1996) Crowding and carrying capacity in the National Park system: toward a social science research agenda. In DW Lime (ed.), Congestion and Crowding in the National Park System. St. Paul: University of Minnesota.

McKinsey \& Company, World Travel \& Tourism Council (2017) Coping with success. Managing overcrowding in tourism destinations. Retrieved from: https://mck.co/3im LbVb. [Accessed 10 September 2020.]

Moyle B, Croy G (2007) Crowding and visitor satisfaction during the off-season: Port Campell National Park. Annals of Leisure Research 10(3-4), 518-531.

Murray J (2013) Likert data: what to use, parametric or non-parametric? International Journal of Business and Social Science 4(11): 258-264.

Oh H (2001) Revisiting importance-performance analysis. Tourism Management, 22(2001): 617-627.

Popp M (2012) Positive and negative urban tourist crowding: Florence, Italy. Tourism Geographies 14(1): 50-72.

Russo AP (2002) The "vicious circle" of tourism development in heritage cities. Annals of Tourism Research 29(1): 165-182.

Sanz-Blas S, Buzova D, Schlesinger W (2019) The sustainability of cruise tourism onshore: the impact of crowding on visitors' satisfaction. Sustainability 11(6): 1-15.

Sayan S, Krymkowski D, Manning R, Valliere W, Rovelstad E (2013) Cultural influence on crowding norms in outdoor recreation: a comparative analysis of visitors to national parks in Turkey and the United States. Environmental Management 52(2): 493-502.

Statistics Norway (2019) 04317: Grunnkretsenes befolkning (G) 1999-2019. (04317: Population of the basic districts (G) 1999-2019). Retrieved from: https://www.ssb. no/statbank/table/04317/. [Accessed 10 September 2020.]

Sun YY, Budruk M (2017) The moderating effect of nationality on crowding perception, its antecedents, and coping behaviours: a study of an urban heritage site in Taiwan. Current Issues in Tourism 20(12): 1246-1264.

Truong T-H, Foster D (2006) Using HOLSAT to evaluate tourist satisfaction at destinations: the case of Australian holidaymakers in Vietnam. Tourism Management 25(5): 842-855.

Vaske JJ, Shelby LB (2008) Crowding as a descriptive indicator and an evaluative standard: results from 30 years of research. Leasure Sciences 30(2): 111-126. 
Yttredal ER, Babri S, Diez M (2019) Antall besøkende og kjøretøy i Geirangerområdet 2018. (Number of visitors and vehicles in Geiranger area 2018). Notat - nr. 4/2019. Norway: Høgskulen i Volda.

Zehrer A, Raich F (2016) The impact of perceived crowding on customer satisfaction. Journal of Hospitality and Tourism Management 29(Jun): 88-98. 
